Pacific Journal of Mathematics

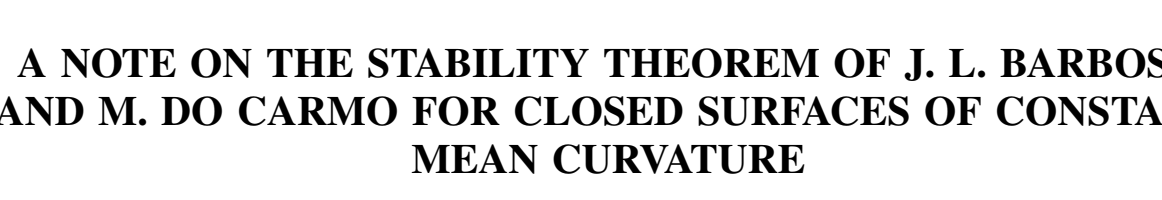




\title{
A NOTE ON THE STABILITY THEOREM \\ OF J. L. BARBOSA AND M. DO CARMO FOR CLOSED SURFACES OF CONSTANT MEAN CURVATURE
}

\author{
HENRY C. Wente
}

The theorem of Barbosa and do Carmo asserts that the only stable compact hypersurface of constant mean curvature in $R^{n+1}$ is the round $n$-sphere. We present an elementary proof of this fact by considering the 2-parameter family $y=s(x+t \xi)$ where $x$ is the constant mean curvature immersion and $\xi$ is the unit normal vector field.

I. Introduction. Let $M$ be a compact oriented $n$-manifold and $x: M \rightarrow R^{n+1}$ an immersion of $M$ into $R^{n+1}$. For such an immersion we compute the $n$-area $A(x)$

$$
A(x)=\int_{M} d S
$$

where $d S$ is the $n$-area element on $M$ induced by the immersion $x$. We can also compute the "oriented" volume $V(x)$ enclosed by the immersed surface $x(M)$. It is given by the formula

$$
V(x)=\frac{1}{n+1} \int_{M}(x \cdot \xi) d S
$$

where $\xi$ is the unit normal vector field determined by the orientation of $M$ and the immersion $x$.

Let $x_{t}:(-\varepsilon, \varepsilon) \times M \rightarrow R^{n+1}$ be a one-parameter family of immersions of $M$ into $R^{n+1}$ with $x_{0}=x$. A necessary and sufficient condition that the area functional $A\left(x_{t}\right)$ have a critical value at $t=0$ for all variations $x_{t}$ for which $V\left(x_{t}\right)$ is constant is that the immersed surface have constant mean curvature $H$. Furthermore, such an immersion is said to be stable if for all volume-preserving perturbations the second derivative of $A\left(x_{t}\right)$ at $t=0$ is non-negative.

In a recent paper [1] J. L. Barbosa and M. do Carmo proved the following theorem.

THEOREM [1]. Let $M$ be a compact oriented n-manifold and let $x: M \rightarrow R^{n+1}$ be an immersion with non-zero constant mean curvature 
$H$. Then $x$ is stable if and only if $x(M) \subset R^{n+1}$ is a (round) sphere $S^{n}$ in $R^{n+1}$.

The stability of the round sphere follows from the isoperimetric inequality. In their proof of the theorem Barbosa and do Carmo consider a particular variation vector field whose first-order change of volume is zero and show that the appropriate second variation is negative unless the surface $x(M)$ is a round sphere. The purpose of this paper is to exhibit a simple one-parameter family of immersions which preserves volume, allows easy calculation of the area and enables us to prove the stability theorem. The family is explicitly described and its variation vector field is precisely the one considered in [1].

II. The alternate proof. Let $x: M \rightarrow R^{n+1}$ be the given compact immersion where we suppose that $x(M)$ has constant mean curvature $H$. Let $x_{t}=x+t \xi$ be the one-parameter family of parallel surfaces to $x$. It is easily seen that $x_{t}$ has the same unit normal vector field as $x$. Furthermore the area $A\left(x_{t}\right)$ and volume $V\left(x_{t}\right)$ enclosed by $x_{t}$ are easily computed.

$$
A\left(x_{t}\right)=\int_{M} \prod_{i=1}^{n}\left(1-k_{i} t\right) d S
$$

where $k_{i}$ are the principal curvatures of $x=x_{0}$. This is a polynomial of degree $n$ in $t$ and may be expanded in the form

$$
\begin{aligned}
A\left(x_{t}\right) & =a_{0}+a_{1} t+a_{2} t^{2}+\cdots+a_{n} t^{n}, \\
a_{0} & =\int d S=A\left(x_{0}\right), \\
a_{1} & =-\int\left(k_{1}+\cdots+k_{n}\right) d S=-n H a_{0}, \\
a_{2} & =\int H_{2} d S, \quad H_{2}=\prod_{i<j} k_{i} k_{j}, \\
a_{k} & =(-1)^{k} \int H_{k} d S, \quad H_{k}=\sum_{i_{1}<\cdots<i_{k}} k_{i_{1}} k_{i_{2}} \cdots k_{i_{k}} .
\end{aligned}
$$

This is an essentially well-known formula. For the case $n=2$ see Stoker [2, p. 352].

The other key formula is also well known, see Stoker [2, p. 352], namely

$$
d V\left(x_{t}\right) / d t=A\left(x_{t}\right) \quad \text { so that }
$$




$$
V\left(x_{t}\right)=v_{0}+v_{1} t+v_{2} t^{2}+\cdots+v_{n+1} t^{n+1}
$$

where $v_{1}=a_{0}, 2 v_{2}=a_{1}=-n H a_{0}$, etc. We shall give proofs of (3) and (5) in the appendix. The family $x_{t}$ is not volume preserving. In order to obtain a volume-preserving family we apply the appropriate homothety. Namely, let $y=s x_{t}$ be a two-parameter family of immersions. Clearly we have

$$
\begin{aligned}
& A\left(s x_{t}\right)=s^{n} A\left(x_{t}\right)=s^{n}\left(a_{0}+a_{1} t+\cdots+a_{n} t^{n}\right) \\
& V\left(s x_{t}\right)=s^{n+1} V\left(x_{t}\right)=s^{n+1}\left(v_{0}+v_{1} t+\cdots+v_{n+1} t^{n+1}\right) .
\end{aligned}
$$

We now determine $s=s(t)$ by setting $V\left(s x_{t}\right)=v_{0}$. By use of formula (8) and the binomial expansion we obtain the series for $s^{n}$ (needing terms only through $t^{2}$ ) and substitute into (7). Calling $A(t) \equiv A\left[s(t) x_{t}\right]$ we find

$$
\begin{aligned}
A(t)= & a_{0}+\left[-\left(\frac{n}{n+1}\right)\left(\frac{v_{1}}{v_{0}}\right) a_{0}+a_{1}\right] t \\
+ & \left\{\left[\frac{n(2 n+1)}{2(n+1)^{2}}\left(\frac{v_{1}}{v_{0}}\right)^{2}-\left(\frac{n}{n+1}\right)\left(\frac{v_{2}}{v_{0}}\right)\right] a_{0}\right. \\
& \left.+\left(\frac{-n}{n+1}\right)\left(\frac{v_{1}}{v_{0}}\right) a_{1}+a_{2}\right\} t^{2}+\cdots .
\end{aligned}
$$

The fact that $A^{\prime}(0)=0$ in (9) leads to

$$
a_{0}+(n+1) H v_{0}=0 \text {. }
$$

Substituting the identities in (6) and (10) into the coefficient of $t^{2}$ in (9) leads to

$$
\begin{aligned}
A^{\prime \prime}(0) / 2 & =-\int_{M}\left[\left(\frac{n^{2}-n}{2}\right) H^{2}-H_{2}\right] d S \\
& =-\frac{1}{2 n} \int_{M}\left(\sum_{i<j}\left(k_{i}-k_{j}\right)^{2}\right) d S .
\end{aligned}
$$

The second equation in (11) is seen as follows [ 1, p. 348]

$$
\begin{gathered}
(n-1) n^{2} H^{2}-2 n H_{2}=(n-1)\left(\sum_{i} k_{i}\right)^{2}-2 n\left(\sum_{i<j} k_{i} k_{j}\right) \\
=(n-1)\left(\sum_{i} k_{i}^{2}\right)+2(n-1) \sum_{i<j} k_{i} k_{j}-2 n \sum_{i<j} k_{i} k_{j} \\
=(n-1)\left(\sum_{i} k_{i}^{2}\right)-2 \sum_{i<j} k_{i} k_{j}=\sum_{i<j}\left(k_{i}-k_{j}\right)^{2} .
\end{gathered}
$$


From (11) we see that if $x$ is not all umbilic then $A^{\prime \prime}(0)$ is negative and the immersion is unstable.

Finally, to find the variational vector field for the family $s(t) x_{t}=$ $s(t)[x+t \xi]$ we differentiate to get

$$
z=d\left(s x_{t}\right) /\left.d t\right|_{t=0}=\dot{s}(0) x+s(0) \xi .
$$

But $s(0)=1$ and an easy calculation using (8) gives $\dot{s}(0)=H$ so that $z=H x+\xi$ and the normal component is $g=z \cdot \xi=H(x \cdot \xi)+1$ which is the variation used by Barbosa and do Carmo.

\section{Appendix.}

Proof of (3). Introduce local coordinates $\left(u_{1}, \ldots, u_{n}\right)$ with corresponding maps $x\left(u_{1}, \ldots, u_{n}\right)$ and normal vector $\xi\left(u_{1}, \ldots, u_{n}\right)$. Denote by $x_{i}=\partial x / \partial u_{i}$ and $\xi_{i}=\partial \xi / \partial u_{i}$. The metric on $M$ induced by the map $x$ is given by the matrix $g=\left(g_{i j}\right)$ where $g_{i j}=\left(x_{i} \cdot x_{j}\right)$ and the element of area for the immersion is $d S=\sqrt{|g|} d u_{1} d u_{2} \cdots d u_{n}$ where $|g|=\operatorname{det}(g)$. For the immersion $x+t \xi$ the corresponding metric tensor is

$$
\tilde{g}_{i j}=(x+t \xi)_{i} \cdot(x+t \xi)_{j}=g_{i j}-2 t h_{i j}+t^{2} \gamma_{i j}
$$

where $h_{i j}=-\left(x_{i} \cdot \xi_{j}\right)$ are the components of the second fundamental form and $\gamma_{i j}=\left(\xi_{i} \cdot \xi_{j}\right)$ determine the third fundamental form. We set $g=\left(g_{i j}\right), h=\left(h_{i j}\right), \gamma=\left(\gamma_{i j}\right)$ and compute

$$
\operatorname{det}(\tilde{g})=\operatorname{det}(g) \cdot \operatorname{det}\left[I-g^{-1}\left(2 t h-t^{2} \gamma\right)\right] .
$$

But the eigenvalues of $g^{-1}\left(2 t h-t^{2} \gamma\right)$ are just $2 t k_{i}-t^{2} k_{i}^{2}$ where $k_{i}$ are the principal curvatures of $x$. Thus

$$
\operatorname{det}(\tilde{g})=\operatorname{det}(g) \cdot \prod_{i}\left(1-k_{i} t\right)^{2}
$$

giving us

$$
d S_{t}=\sqrt{|\tilde{g}|} d u_{1} d u_{2} \cdots d u_{n}=\prod_{i}\left(1-k_{i} t\right) d S
$$

Proof of (5). It is sufficient to prove (5) when $t=0$.

$$
V\left(x_{t}\right)=\frac{1}{n+1} \int_{M}((x+t \xi) \cdot \xi) \prod_{i}\left(1-k_{i} t\right) d S .
$$

Therefore

$$
\left.\frac{d}{d t} V\left(x_{t}\right)\right|_{t=0}=\frac{1}{n+1} \int_{M}[1-n H(x \cdot \xi)] d S
$$


Thus it suffices to show

$$
\int_{M}[1+H(x \cdot \xi)] d S=0 .
$$

A proof of this identity in the case $n=2$ may be found in Stoker [2, p. 303]. It is equivalent to (10). For the general case consider the $(n-1)$-form on $M$ given by

$$
\omega=\{d x, \ldots(n-1) \text { times } \ldots, d x, x, \xi\}
$$

where we have described each column of an $(n+1) \times(n+1)$ matrix and $\omega$ is the determinant of the matrix.

$$
d \omega=\{d x, \ldots, d x, d x, \xi\}+\{d x, \ldots, d x, x, d \xi\} .
$$

A straightforward calculation gives

$$
\begin{aligned}
& \{d x, \ldots, d x, d x, \xi\}=n ! d S, \\
& \{d x, \ldots, d x, x, d \xi\}=n ! H(x \cdot \xi) d S .
\end{aligned}
$$

Thus $d \omega=n ![1+H(x \cdot \xi)] d S$ and the assertion follows.

\section{REFERENCES}

[1] J. L. Barbosa and M. do Carmo, Stability of hypersurfaces of constant mean curvature, Math. Zeitschrift, 185 (1984), 339-353.

[2] J. L. Stoker, Differential Geometry, Wiley-Interscience, (1969).

Received March 15, 1989.

UNIVERSITY OF TOLEDO

TOLEDO, OH 43606 



\title{
PACIFIC JOURNAL OF MATHEMATICS EDITORS
}

\author{
V. S. VARADARAJAN \\ (Managing Editor) \\ University of California \\ Los Angeles, CA 90024-1555-05 \\ Herbert Clemens \\ University of Utah \\ Salt Lake City, UT 84112 \\ THOMAS ENRIGHT \\ University of California, San Diego \\ La Jolla, CA 92093
}

R. FINN

Stanford University

Stanford, CA 94305

Hermann FlaschKa

University of Arizona

Tucson, AZ 85721

VAUGHaN F. R. JoNes

University of California

Berkeley, CA 94720

Steven Kerckhoff

Stanford University

Stanford, CA 94305

\section{C. MOORE}

University of California

Berkeley, CA 94720

Martin ScharlemanN

University of California

Santa Barbara, CA 93106

HAROLD STARK

University of California, San Diego

La Jolla, CA 92093
R. ARENS
E. F. BECKENBACH
F. WolF
K. YoshidA

\section{ASSOCIATE EDITORS}

\begin{tabular}{ll}
\multicolumn{1}{c}{ SUD-1982) } & \multicolumn{1}{c}{$(1904-1989)$} \\
UNIVERSITY OF ARIZONA & UNIVERSITY OF OREGON \\
UNIVERSITY OF BRITISH COLUMBIA & UNIVERSITY OF SOUTHERN CALIFORNIA \\
CALIFORNIA INSTITUTE OF TECHNOLOGY & STANFORD UNIVERSITY \\
UNIVERSITY OF CALIFORNIA & UNIVERSITY OF HAWAII \\
MONTANA STATE UNIVERSITY & UNIVERSITY OF TOKYO \\
UNIVERSITY OF NEVADA, RENO & UNIVERSITY OF UTAH \\
NEW MEXICO STATE UNIVERSITY & WASHINGTON STATE UNIVERSITY \\
OREGON STATE UNIVERSITY & UNIVERSITY OF WASHINGTON \\
\hline
\end{tabular}

The Supporting Institutions listed above contribute to the cost of publication of this Journal, but they are not owners or publishers and have no responsibility for its content or policies.

\begin{abstract}
Mathematical papers intended for publication in the Pacific Journal of Mathematics should be in typed form or offset-reproduced (not dittoed), double spaced with large margins. Please do not use built up fractions in the text of the manuscript. However, you may use them in the displayed equations. Underline Greek letters in red, German in green, and script in blue. The first paragraph must be capable of being used separately as a synopsis of the entire paper. In particular it should contain no bibliographic references. Please propose a heading for the odd numbered pages of less than 35 characters. Manuscripts, in triplicate, may be sent to any one of the editors. Please classify according to the 1980 Mathematics Subject Classification (1985 Revision) scheme which can be found in the December index volumes of Mathematical Reviews. Supply name and address of author to whom proofs should be sent. All other communications should be addressed to the managing editor, or Elaine Barth, University of California, Los Angeles, California 90024-1555-05.

There are page-charges associated with articles appearing in the Pacific Journal of Mathematics. These charges are expected to be paid by the author's University, Government Agency or Company. If the author or authors do not have access to such Institutional support these charges are waived. Single authors will receive 50 free reprints; joint authors will receive a total of 100 free reprints. Additional copies may be obtained at cost in multiples of 50 .
\end{abstract}

The Pacific Journal of Mathematics (ISSN 0030-8730) is published monthly except for July and August. Regular subscription rate: $\$ 190.00$ a year (10 issues). Special rate: $\$ 95.00$ a year to individual members of supporting institutions.

Subscriptions, orders for numbers issued in the last three calendar years, and changes of address should be sent to Pacific Journal of Mathematics, P.O. Box 969, Carmel Valley, CA 93924, U.S.A. Old back numbers obtainable from Kraus Periodicals Co., Route 100, Millwood, NY 10546.

The Pacific Journal of Mathematics at P.O. Box 969, Carmel Valley, CA 93924 (ISSN 0030-8730) is published monthly except for July and August. Second-class postage paid at Carmel Valley, California 93924, and additional mailing offices. Postmaster: send address changes to Pacific Journal of Mathematics, P.O. Box 969, Carmel Valley, CA 93924.

PUBLISHED BY PACIFIC JOURNAL OF MATHEMATICS, A NON-PROFIT CORPORATION Copyright (C) 1991 by Pacific Journal of Mathematics 